\section{References}

1. Horan TC, Andrus M, Dudeck MA. CDC/NHSN surveillance definition of healthcare-associated infection and criteria for specific types of infections in the acute care setting. Am J Infect Control 2008;36:309-332.

2. Murni IK, Duke T, Kinney S, Daley AJ, Soenarto Y. Reducing hospitalacquired infections and improving the rational use of antibiotics in a developing country: an effectiveness study. Arch Dis Childhood 2014;100:454-459.

3. Klevens JR. Edwards CL, Richards Jr TC, et al. Estimating healthcareassociated infections and deaths in US hospitals. Public Health Rep 2007;122:160-166.

4. Scott R. The direct medical costs of health care-associated infections in US hospitals and the benefits of prevention. Centers for Disease Control and Prevention website. http://www.cdc.gov/HAI/pdfs/hai/Scott_CostPaper.pdf. Accessed July 19, 2019.
5. Graves N, Halton K, Jarvis W. Economics and Preventing HealthcareAcquired Infection. New York: Springer; 2009.

6. Pittet D. Compliance with hand disinfection and its impact on hospitalacquired infections. J Hosp Infect 2001;48 supplement A: S40-S46.

7. Curtis L. Prevention of hospital-acquired infections: review of nonpharmacological interventions. J Hosp Infect 2008;69:204-219.

8. Carboneau C, Benge E, Jaco MT, Robinson M. A lean six-sigma team increases hand hygiene compliance and reduces hospital-acquired MRSA infections by 51\%. J Healthcare Qual 2010;32:61-70.

9. Hübner N-O, Hübner C, Kramer A. Impact of health campaign on hand hygiene with alcohol-based hand rubs in a nonclinical setting. $J$ Hosp Infect 2013;83 suppl 1:S23-S28.

10. Wenzel RP, Osterman CA, Hunting KJ, Gwaltney JM. Hospital-acquired infections. I. Surveillance in a university hospital. Am J Epidemiol 1976;103:251-260.

\title{
Illicit drug users, alcoholics, and psychiatric patients: Staphylococcus aureus and methicillin-resistant Staphylococcus aureus colonization on the border between community and healthcare settings
}

\author{
Maíris Alarcão Duarte de Oliveira Silvestre MD, $\mathrm{PhD}^{1}$, Marina Barbosa RN, MSc${ }^{1}$, Nathalia Bibiana Teixeira MD², \\ Danilo Flávio Moraes Riboli MSc², Matheus Cristovam de Souza PhD², Maria de Lourdes Ribeiro de Souza da Cunha PhD² \\ and Carlos Magno Castelo Branco Fortaleza MD, $\mathrm{PhD}^{1}$ (c) \\ ${ }^{1}$ Department of Tropical Diseases, Faculdade de Medicina de Botucatu (Botucatu School of Medicine), Universidade Estadual Paulista (São Paulo State \\ University, UNESP). City of Botucatu, São Paulo State, Brazil and ${ }^{2}$ Department of Microbiology and Immunology, Instituto de Biociências de Botucatu (Botucatu \\ Institute of Biosciences), Universidade Estadual Paulista (São Paulo State University, UNESP). City of Botucatu, São Paulo State, Brazil
}

To the Editor-Even though methicillin-resistant Staphylococcus aureus (MRSA) colonization and infections have been extensively reported among users who inject illicit drugs, ${ }^{1,2}$ studies addressing other illicit drug users (IDUs), ${ }^{3}$ alcoholics and psychiatric patients are scarce. ${ }^{4}$ Those latter groups are of special concern when admitted to acute-care or long-term care facilities. In these settings, MRSA colonization may be a predisposing factor for invasive infection and/or for spread of potentially hazardous clones. ${ }^{5}$ With that in mind, we conducted a survey for asymptomatic colonization with overall Staphylococcus aureus and MRSA among patients from 2 psychiatric care hospitals in Botucatu, inner Brazil. Notably, the use of injection drugs is extremely rare in this country, while there is endemic prevalence of use of inhaled cocaine, crack cocaine and marijuana smoking, and abuse of alcoholic beverages. ${ }^{6}$

The study was conducted a reference hospital for short-term admissions of IDUs and alcoholics (70 beds) and a psychiatric hospital with both short and long-term admissions ( 80 beds). Nasal and oropharyngeal swabs were collected from patients upon admission, except for those in long-term care, who had their swabs

Author for correspondence: Carlos Magno Castelo Branco Fortaleza, E-mail: carlos. fortaleza@unesp.br

Cite this article: Silvestre MADdO, et al. (2021). Illicit drug users, alcoholics, and psychiatric patients: Staphylococcus aureus and methicillin-resistant Staphylococcus aureus colonization on the border between community and healthcare settings. Infection Control \& Hospital Epidemiology, 42: 1544-1546, https://doi.org/10.1017/ ice. 2020.1330 collected during their hospital stay, which often lasted years. Species identification and antimicrobial susceptibility tests followed current microbiology practices. MRSA was characterized by amplification of the mecA gene and typing of the staphylococcal chromosome cassette (SCCmec). Molecular strain typing was performed with smaI- or ApaI-based pulsed-field gel electrophoresis (PFGE). A questionnaire was applied to study subjects in the moment of the collection of swabs, and extensive review of their medical charts was performed. Briefly, we assessed information on demographics, sexual behavior, history of previous incarceration, patterns of use of alcohol and illicit drugs. We also recorded the following data for the year previous to inclusion in our study: admissions to acute-care hospitals, invasive procedures (including surgeries), use of antimicrobials, respiratory infection, and skin or soft-tissue infections. Statistical analysis including univariate and multivariable (Poisson regression) models was performed using SPSS version 20 software (IBM, Armonk, NY). We used a stepwise forward strategy to select variables for the multivariable models, with $P<.10$ as a criteria for both entering and staying in the models.

In total, 220 subjects were included in our study: 138 from the IDU/alcoholics facility and 82 from the psychiatric hospital. Overall S. aureus and MRSA colonization prevalence rates were as follows: (1) IDUs/alcoholics facility, 28.3\% (95\% confidence interval $[\mathrm{CI}], 20.1 \%-36.6 \%)$ for $S$. aureus and $2.9 \%(95 \%$ CI, $0.8 \%-7.3 \%$ ) for MRSA and (2) psychiatric hospital, $24.3 \%$ (95\% CI, $15.6 \%-35.1 \%)$ for S. aureus and $7.3 \%$ (95\% CI,

(c) The Author(s), 2020. Published by Cambridge University Press on behalf of The Society for Healthcare Epidemiology of America This is an Open Access article, distributed under the terms of the Creative Commons Attribution licence (http://creativecommons.org/licenses/by/4.0/), which permits unrestricted re-use, distribution, and reproduction in any medium, provided the original work is properly cited. 


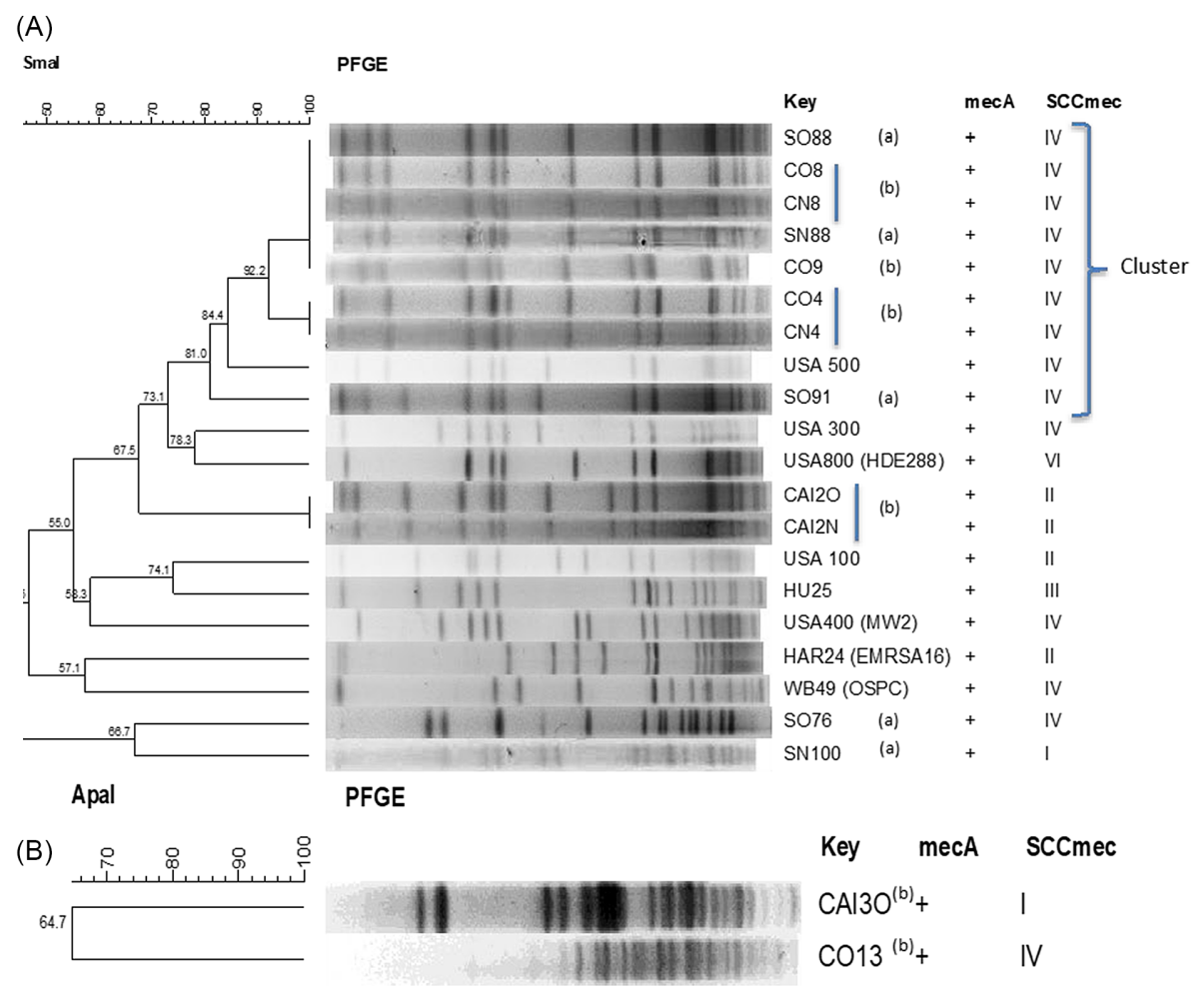

Fig. 1. Dendrograms showing MRSA isolates recovered in the study, together with international reference clones. (A) Isolates typed with Smal. (B) Isolates that required $A p a$ l for typing. Isolates from the same subject are grouped with vertical lines. The origin of isolates was as follows: (a) subjects in hospital for drug and alcohol addiction (HRCAD); (b) subjects from the psychiatric hospital (CPA). Note. N, nasal swab; O, oropharyngeal swab.
2.7\%-15.3\%) for MRSA. Notably, in this latter psychiatric hospital, patients in acute-care admissions presented significantly $(P<.05)$ higher prevalence of both $S$. aureus $(39.4 \%$ vs $14.3 \%$ in long-term residents) and MRSA ( $12.1 \%$ vs $4.1 \%)$.

The analysis of predictors for $S$. aureus colonization is presented in Supplementary Tables 1 and 2 (online). Briefly, among patients from the IDU/alcoholics facility, the use of inhaled cocaine was associated with greater likelihood of colonization (prevalence ratio $[\mathrm{PR}], 2.26$; 95\% confidence interval $[\mathrm{CI}], 1.02-5.00 ; P=.04$ ). Among patients admitted to the psychiatric hospital, overall $S$. aureus colonization was negatively associated with age $(\mathrm{PR}, 0.96$; 95\% CI, 0.93-0.99; $P=.03$ ).

Supplementary Table 3 (online) lists the characteristics of 10 patients harboring MRSA. Briefly, 5 had diagnoses of alcoholism, 5 used illicit drugs (mostly crack cocaine), and 4 reported previous hospital admissions. Counterintuitively, study participants with recent hospital admissions carried MRSA with the usually community-associated SCCmec type IV. The number of patients colonized with MRSA was too small to warrant statistical analysis of predictors, yet molecular typing results were noteworthy. MRSA isolates harbored SCCmec types IV (7 patients), II (2 patients) and I (1 patient). There was no association of SCCmec type with previous hospital admissions. Most remarkably, a single similarity cluster grouped 5 of 10 MRSA identified in our survey, along with the USA500 clone (Fig. 1).

In the past decade, it has been increasingly recognized that the classical distinction between community-associated (CA-) and healthcare-associated (HA-) MRSA is not precise. ${ }^{7}$ Hospitals that harbor short- and long-term patients with behavioral disorders are an interesting, perhaps intermediate, setting for MRSA transmission. Not surprisingly, we found both clones that are usually associated with community-associated (type IV) and healthcareassociated (type I and II) MRSA infections. Interestingly, the patients colonized with SCCmec I and II isolates reported no history of recent hospital admissions.

We interpret our findings to indicate potential instances of introduction of MRSA strains in the hospitals, either from IDUs or patients recently admitted with psychiatric disorders. The presence of a cluster grouping half MRSA isolates is noteworthy. Although some transfer of patients between the 2 hospitals occurred, no MRSA carrier in this study had been admitted to both facilities. Transmission in community networks of illicit drug users is always possible, and this hypothesis is coherent with findings of previous studies. ${ }^{8,9}$ Also, interesting simulations using agent-based modelling have emphasized the relevance of community networks in the spread of MRSA clones. ${ }^{10}$

In this study, SCCmec types usually related to community-associated (type IV) and healthcare-associated infections (types I and II). However, there was no epidemiological link between SCCmec type and previous history of admission to an acute-care hospital.

Our study has some limitations, including the relatively small sample population. Also, we did not perform multilocus sequence typing (MLST). However, the simultaneous use of molecular and classical epidemiology strengthened the analysis of our findings.

In conclusion, overall $S$. aureus colonization was similar to that in the general population, but we found relevant rates of MRSA carriage among the study groups. Those patients may be either at greater risk for MRSA infection or act as spreaders of potentially hazardous clones. In both cases, they constitute a target population for interventions aimed at preventing and controlling severe staphylococcal infections.

Acknowledgments. The funding agencies did not influence the conduct of the study, the analysis of data, the decision to publish, or the content of the manuscript.

Financial support. C.M.C.B.F. received a research grant from the São Paulo State Research Foundation (FAPESP, Process 11/06988-2). M.C.S. received 
student grant from the same agency (FAPESP, Process 17/01575-8). M.B. received student grant from the National Foundation for Research (CNPq).

Conflicts of interest. All authors report no conflicts of interest relevant to this article.

Supplementary material. To view supplementary material for this article, please visit https://doi.org/10.1017/ice.2020.1330

\section{References}

1. Lloyd-Smith E, Hull MW, Tyndall MW, et al. Community-associated methicillin-resistant Staphylococcus aureus is prevalent in wounds of community-based injection drug users. Epidemiol Infect 2010 May;138:713-720.

2. Huang H, Cohen SH, King JH, Monchaud C, Nguyen H, Flynn NM. Injecting drug use and community-associated methicillin-resistant Staphylococcus aureus infection. Diagn Microbiol Infect Dis 2008;60: 347-350.

3. Dahlman D, Jalalvand F, Blomé MA, et al. High perineal and overall frequency of Staphylococcus aureus in people who inject drugs, compared to non-injectors. Curr Microbiol 2017;74:159-167.
4. Farley JE, Ross T, Krall J, et al. Prevalence, risk factors, and molecular epidemiology of methicillin-resistant Staphylococcus aureus nasal and axillary colonization among psychiatric patients on admission to an academic medical center. Am J Infect Control 2013;41:199-203.

5. Jarvis WR. The epidemiology of colonization. Infect Control Hosp Epidemiol 1996;17:47-52.

6. Inciardi JA, Surratt HL, Pechansky F, et al. Changing patterns of cocaine use and HIV risks in the south of Brazil. J Psychoactive Drugs 2006;38:305-310.

7. Bal AM, Coombs GW, Holden MT, et al. Genomic insights into the emergence and spread of international clones of healthcare-, community- and livestock-associated meticillin-resistant Staphylococcus aureus: blurring of the traditional definitions. J Glob Antimicrob Resis 2016;6:95-101.

8. Gwizdala RA, Miller M, Bhat M, et al. Staphylococcus aureus colonization and infection among drug users: identification of hidden networks. Am J Public Health 2011;101:1268-1276.

9. Popovich KJ, Snitkin E, Green SJ, et al. Genomic epidemiology of USA300 methicillin-resistant Staphylococcus aureus in an urban community. Clin Infect Dis 2016;62:37-44.

10. Macal CM, North MJ, Collier N, et al. Modeling the transmission of community-associated methicillin-resistant Staphylococcus aureus: a dynamic agent-based simulation. J Transl Med 2014;12:124. 